\title{
Sentiment Analysis of Cyberbullying on Twitter Using SentiStrength
}

\author{
${ }^{1}$ Ulfa Khaira, ${ }^{2}$ Ragil Johanda, ${ }^{3}$ Pradita Eko Prasetyo Utomo, ${ }^{4}$ Tri Suratno \\ 1,2,3,4 Program Studi Sistem Informasi, Universitas Jambi \\ Email: ${ }^{1}$ ulfa.ilkom@gmail.com, ${ }^{2}$ ragiljohanda1@gmail.com, ${ }^{3}$ pradita.eko@unja.ac.id, ${ }^{4}$ trie123@gmail.com
}

\section{Article Info}

Article history:

Received February $02^{\text {th }}, 2020$

Revised March $05^{\text {th }}, 2020$

Accepted March 04 ${ }^{\text {th }}, 2020$

\section{Keyword:}

Cyberbullying

Sentiment analysis

SentiStrength

Twitter

\begin{abstract}
Cyberbullying is a form of bullying that takes place across virtually every social media platform. Twitter is a form of social media that allows users to exchange information. Bullying has been a growing problem on Twitter over the past few years. Sentiment analysis is done to identify the element of bullying in a tweet. Sentiments are divided into 3 classes, namely Bullying, Non-Bullying and neutral. There are three steps to classify cyberbullying i.e. collection of data set, preprocessing data, and classification process. This research used sentiStrength, an algorithm which uses a lexicon based approach. This SentiStrength lexicon contains the weight of its sentiment strength. The assessment results from 454 tweets data obtained 161 tweet non-bullying (35.4\%), 87 tweet neutral (19.1\%), and 206 tweet bullying $(45.4 \%)$. This research produces an accuracy value of $60.5 \%$.
\end{abstract}

Copyright () 2020 Puzzle Research Data Technology

\section{Corresponding Author:}

Ulfa Khaira,

Program Studi Sistem Informasi, Universitas Jambi,

Jalan Raya Jambi-Ma.Bulian KM.15

Email: ulfa.ilkom@gmail.com

DOI: http://dx.doi.org/10.24014/ijaidm.v3i1.9145

\section{PENDAHULUAN}

Di era globalisasi seperti saat sekarang ini, segala bentuk kemudahan terjanjikan bagi kehidupan manusia. Kehadiran teknologi informasi memiliki pengaruh yang besar bagi peradaban manusia. Informasi dapat menyebar secara luas dalam waktu yang singkat berkat kemajuan teknologi, salah satu bentuknya yaitu penggunaan media sosial.

Media sosial merupakan platform media yang memfokuskan pada eksistensi pengguna serta memfasilitasi mereka dalam beraktivitas maupun berkolaborasi. Karena itu media sosial dapat dilihat sebagai medium (fasilitator) online yang menguatkan hubungan antar pengguna sekaligus sebuah ikatan sosial. Melalui media sosial yang semakin banyak berkembang memungkinkan informasi menyebar dengan mudah di masyarakat. Informasi dalam bentuk apa pun dapat disebarluaskan dengan mudah dan cepat sehingga mempengaruhi cara pandang, gaya hidup, serta budaya suatu bangsa[1].

Salah satu media sosial yang sangat populer saat ini yaitu Twitter. Twitter merupakan media sosial yang berbentuk microblogging atau ngeblog secara singkat dalam satu paragraf dengan maksimal 280 huruf, karena jumlah huruf dalam satu kali tweet terbatas/dibatasi. Pengguna Twitter terdiri dari berbagai kalangan, seperti pejabat, selebritis, artis, hingga masyarakat biasa pada umumnya. Akan tetapi, kemudahan yang diberikan untuk berbagi informasi melalui media sosial tak luput dari penyalahgunaan yang dilakukan oleh penggunanya. Salah satu bentuk penyalahgunaan tersebut yaitu cyberbullying.

Cyberbullying merupakan bentuk tindak kekerasan yang dilakukan oleh seseorang terhadap korbannya di dunia maya, dimana korban dihina, diejek, dipermalukan dan diintimidasi oleh pelaku. Dampak dari cyberbullying yaitu mempengaruhi mental korban, bahkan banyak dari korban bullying berakhir dengan bunuh diri karena tidak tahan dengan banyak tekanan. Ada hubungan positif dan signifikan antara perilaku pelaku cyberbullying dan perilaku korban cyberbullying yang mana semakin reaktif perilaku pelaku cyberbullying maka semakin reaktif pula perilaku korban cyberbullying. Hal ini membuktikan betapa besarnya pengaruh cyberbullying terhadap kehidupan sosial[2]. 
Analisis sentimen merupakan sub bagian dari Natural Language Processing (NLP) yang fokus pada menentukan perasaan yang terkandung pada sebuah teks. Analisis sentimen dikenal dengan opinion mining yang merupakan proses memahami, mengekstrak dan mengolah data tekstual secara otomatis untuk mendapatkan informasi sentimen yang terkandung dalam suatu kalimat [3]. Ide dasar dari analisis setimen adalah untuk mendeteksi polaritas teks pada dokumen, kalimat, dan tweet. Polaritas sentimen terbagi tiga yaitu positif, negatif, dan netral.

Berbagai penelitian terkait analisis sentimen telah banyak dilakukan. Terdapat dua pendekatan untuk melakukan analisis sentimen, pendekatan yang pertama adalah berbasis machine learning [4] yaitu dengan melatih classifier pada dataset yang telah dilabelkan secara manual. Pendekatan yang kedua adalah berbasis leksikal [5] yang tidak memerlukan pelatihan dataset, mengukur polaritas suatu kalimat atau dokumen berdasarkan pada sentimen kata-kata dan frasa-frasa sambil menerapkan aturan-aturan tertentu yang diambil dari Iinguistik. Penelitian ini akan menganalisis sentimen terkait cyberbullying dari komentar masyarakat pada media sosial Twitter, untuk itu diperlukan metode yang dapat mengklasifikasikan komentar ke dalam kelas positif, negatif, dan netral. Kelas negatif berarti komentar yang mengandung elemen cyberbullying, kelas positif berarti komentar mengandung unsur motivasi atau dukungan, dan kelas netral adalah komentar yang tidak mengandung elemen cyberbullying.

Dalam penelitian sebelumnya [11], SentiStrength dievaluasi pada beberapa dataset yang terdiri dari teks bahasa Inggris. Dalam penelitian ini, kami mereplikasi studi sebelumnya untuk teks bahasa Indonesia. Penelitian ini menggunakan metode SentiStrength berbasis kamus/leksikon. Kamus/leksikon SentiStrength berisi terms serta bobot kekuatan sentimennya. Metode SentiStrength menggunakan daftar idiom dan emotikon serta beberapa aturan lain seperti peningkatan kekuatan sentimen ketika huruf kapital digunakan[6].

\section{METODE PENELITIAN}

\subsection{Prosedur Penelitian}

Proses sentimen analisis terkait cyberbullying dari komentar masyarakat pada media sosial Twitter, dapat dilihat pada Gambar 1. Tahap pertama dilakukan pengumpulan dan pelabelan data, selanjutnya tahap praproses data, klasifikasi tweet, dan evaluasi hasil klasifikasi.

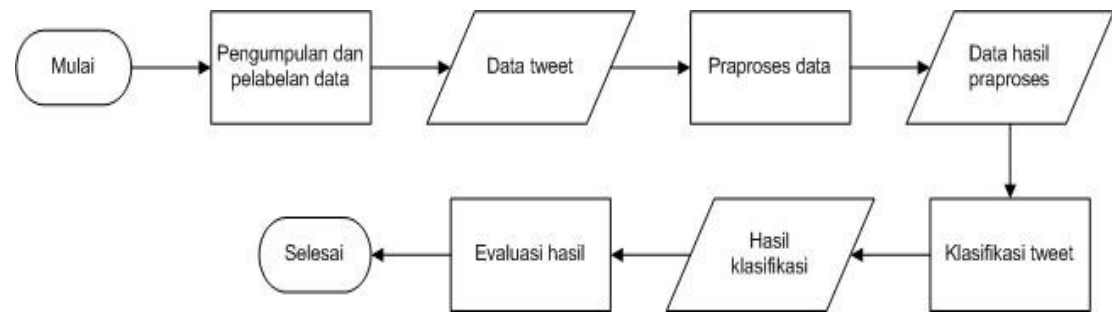

Gambar 1. Prosedur Penelitian

\subsection{Pengumpulan dan Pelabelan Data}

Dataset yang digunakan dalam penelitian ini merupakan data tweet dari Twitter (scraping). Menggunakan Twitter API. Jumlah tweet yang digunakan sebanyak 500 tweet (data awal). Kata kunci yang digunakan dalam pengambilan data tweet merupakan frasa atau kalimat yang mengandung maksud buruk atau mem-bully. Salah satu contohnya yaitu "dasar kampungan". Pelabelan setiap data dilakukan secara manual, label yang diberikan ada 3 kelas, yaitu kelas positif, kelas negatif, dan kelas netral. Kelas negatif berarti komentar yang mengandung elemen cyberbullying, kelas positif berarti komentar mengandung unsur motivasi atau dukungan, dan kelas netral adalah komentar yang tidak mengandung elemen cyberbullying.

Adapun tools yang digunakan dalam penelitian ini di antaranya: plugin python-twitter, pandas, numpy, nltk, sastrawi, textblob, spacy, matplotlib, dan wordcloud. Ditulis dalam lingkungan bahasa pemrograman Python melalui IDE Jupyter.

\subsection{Praproses Data}

Data tweet yang terkumpul masih berbentuk data yang belum terstruktur sehingga perlu dilakukan praproses untuk mendapatkan data yang bersih agar proses klasifikasi lebih akurat. Tahapan praproses data terdiri dari proses tokenizing, filtering, dan stemming.

1. Proses Tokenizing

Tokenisasi adalah tahap pemotongan string input menjadi beberapa potongan yang disebut token berdasarkan tiap kata yang menyusunnya. Token yang dihasilkan berupa kata tunggal yang akan menjadi term sebagai penciri untuk klasifikasi sentiment. Karakter spasi digunakan sebagai pemisah kata yang akan dipotong. Sebelum dilakukan tokenisasi, data tweet diubah ke dalam bentuk

IJAIDM Vol. 3, No. 1, March 2020: $21-27$ 
lowercase. URL, username, dan simbol dihapus, serta kesalahan pada pengetikan atau ejaan diperbaiki [7].

2. Filtering

Tahap Filtering adalah tahap mengambil kata-kata penting dari hasil token. Pada tahapan ini stopword akan dihilangkan untuk mengurangi jumlah kata yang disimpan oleh sistem . Stopword adalah daftar kata umum yang dianggap tidak memiliki makna. Contoh dari stopwords antara lain "yang", "dan", "dari"[8].

3. Stemming

Pada tahapan Stemming dilakukan proses untuk mencari stem (kata dasar) dari kata hasil filtering dengan cara menghilangkan imbuhan seperti berupa awalan dan akhiran. Terdapat dua aturan dalam melakukan stemming yaitu dengan pendekatan kamus dan pendekatan aturan[9].

\subsection{Klasifikasi Tweet}

Pada Penelitian ini, klasifikasi tweet dilakukan dengan menggunakan algoritma SentiStrength. SentiStrength merupakan algoritma classifier menggunakan pendekatan berbasis leksikon dengan berfokus pada kekuatan sentiment di sebuah teks singkat[10]. SentiStrength memanfaatkan leksikal dengan sistem dual scale (positif-negatif), menurut penelitian psikologi bahwa manusia dapat merasakan emosi positif dan emosi negatif secara bersamaan, sampai di batas tertentu secara mandiri[11]. SentiStrength akan menghasilkan nilai yang positif dan nilai yang negatif. Jangkauan nilai dimulai dari angka 1 sampai 5 . Nilai 1 menunjukkan kalimat tersebut tidak memiliki sentimen positif maupun negatif, sedangkan nilai 5 menunjukkan kalimat tersebut memiliki sentimen sangat positif atau sangat negatif. Nilai akhir pada sebuah kalimat ditentukan dari skor positif tertinggi dan skor negatif tertinggi dari kata-kata penyusunnya. Contoh : "Aku benar-benar mencintaimu tapi tidak suka adik dingin Anda". Maka hasil parsing sebagai berikut : Aku benar-benar mencintaimu(4) tapi tidak(-3) suka adik dingin(-3) anda <skor: 4,-3>. Angka dalam (...) menunjukan angka kekuatan sentimen pada setiap kata penyusun, sedangkan angka di dalam tanda "<skor: ..., ...>" mengindikasikan skor akhir kalimat. Keputusan akhir sentimen didasarkan pada aturan:

if positive value $>$ negative value then positive sentiment. if positive value $<$ negative value then negative sentiment. if positive value $=$ negative value then neutral sentiment.

Kalimat tersebut di atas memiliki nilai positif lebih besar dari pada nilai negatif sehingga dapat diklasifikasikan kepada sentimen positif.

\subsection{Uji Akurasi Klasifikasi Tweet}

Pengujian klasifikasi sentimen dilakukan dengan membandingkan antara data prediksi dan data aktual. Data prediksi berupa hasil klasifikasi yang dihasilkan oleh algoritma yang digunakan, sedangkan data aktual berupa hasil klasifikasi yang dihasilkan dari oleh manusia dengan pelabelan manual. Karena algoritma SentiStrength bersifat unsupervised, maka tidak dibutuhkan data latih untuk mengklasifikasi sentimen.

Pada penelitian ini pengujian yang digunakan adalah akurasi. Akurasi menunjukkan perbandingan kasus yang terklasifikasi benar dengan jumlah semua kasus, Untuk menghitung tingkat akurasi klasifikasi, digunakan metode confusion matrix, atau dalam unsupervised learning biasanya dikenal dengan istilah matching matrix. Tabel matriks terdiri dari data aktual dan data prediksi, dengan model confusion matrix 3x 3 atau disebut juga dengan istilah extended confusion matrix, yang ditunjukkan pada Tabel 1.

Tabel 1. Tabel Confusion Matrix

\begin{tabular}{ccccc}
\hline & & \multicolumn{3}{c}{ Data Prediksi } \\
\cline { 3 - 5 } & & Kelas A & Kelas B & Kelas C \\
\hline \multirow{4}{*}{ Data Aktual } & Kelas A & AA & AB & AC \\
& Kelas B & BA & BB & BC \\
& Kelas C & CA & CB & CC \\
\hline
\end{tabular}

Perhitungan akurasi ditunjukkan pada persamaan 1.

$$
\text { Akurasi }=\frac{A A+B B+C C}{A A+A B+A C+B A+B B+B C+C A+C B+C C}
$$




\section{HASIL DAN PEMBAHASAN}

\subsection{Praproses Data}

Praproses merupakan tahap awal dari text mining untuk mengubah data sesuai dengan format atau bentuk yang diperlukan. Tahapan praproses data terdiri dari proses tokenisasi, filtering dan stemming.

\section{Proses Tokenisasi}

Sebelum dilakukan tokenisasi, dilakukan normalisasi data yang meliputi pembersihan data tweet (Cleaning) yaitu menghapus URL, username, mention, serta simbol-simbol seperti tanda tanya dan tanda seru. Data diubah ke dalam bentuk lowercase atau dikenal dengan istilah case folding dan selanjutnya dilakukan kegiatan Spelling correction yaitu memperbaiki kesalahan penulisan atau dikenal dengan istilah typo, jika typo ini tidak diperbaiki, maka dapat mempengaruhi hasil analisis yang diperoleh. Proses normalisasi data disajikan pada Tabel 2.

Tabel 2. Proses Normalisasi

\begin{tabular}{|c|c|c|}
\hline Proses & Sebelum & Sesudah \\
\hline Cleaning & $\begin{array}{l}\text { @xyz Dia tampak menyesal setelah } \\
\text { menjuaal Tanah warisAn Ibunyaa, } \\
\text { ANAK DURHAKA }\end{array}$ & $\begin{array}{l}\text { Dia tampak menyesal setelah menjuaal } \\
\text { Tanah warisAn Ibunyaa ANAK } \\
\text { DURHAKA }\end{array}$ \\
\hline Case folding & $\begin{array}{l}\text { Dia tampak menyesal setelah menjuaal } \\
\text { Tanah warisAn Ibunyaa ANAK } \\
\text { DURHAKA }\end{array}$ & $\begin{array}{l}\text { dia tampak menyesal setelah menjuaal } \\
\text { tanah warisan ibunyaa anak durhaka }\end{array}$ \\
\hline Spelling Correction & $\begin{array}{l}\text { dia tampak menyesal setelah menjuaal } \\
\text { tanah warisan ibunyaa anak durhaka }\end{array}$ & $\begin{array}{l}\text { dia tampak menyesal setelah menjual } \\
\text { tanah warisan ibunya anak durhaka }\end{array}$ \\
\hline
\end{tabular}

Proses tokenizing dilakukan dengan memotong string input berdasarkan tiap kata yang menyusunnya, dihasilkan kata tunggal yang menjadi term sebagai penciri untuk klasifikasi sentimen.

Tabel 3. Proses tokenizing

\begin{tabular}{lll}
\hline Sebelum & Sesudah & \\
\hline $\begin{array}{l}\text { dia tampak menyesal setelah menjual tanah warisan } \\
\text { ibunya anak durhaka }\end{array}$ & $\begin{array}{l}\text { dia tampak menyesal setelah menjual tanah warisan } \\
\text { ibunya anak durhaka }\end{array}$ \\
\hline
\end{tabular}

\section{Proses filtering}

Pada proses ini dilakukan pengambilan kata-kata penting dari hasil token, stopword akan dihilangkan untuk mengurangi jumlah kata yang disimpan oleh sistem, Stopwords merupakan kata umum yang muncul dalam jumlah besar dan dianggap tidak memiliki makna. Stopwords yang digunakan berasal dari analisis kata dasar yang dilakukan oleh Tala[12]. Proses filtering disajikan pada Tabel 4.

Tabel 4. Proses Filtering

\begin{tabular}{|c|c|}
\hline Sebelum & Sesudah \\
\hline $\begin{array}{l}\text { dia tampak menyesal setelah menjual tanah warisan } \\
\text { ibunya anak durhaka }\end{array}$ & menyesal menjual tanah warisan ibunya anak durhaka \\
\hline
\end{tabular}

\section{Proses Stemming}

Pada tahapan ini dilakukan proses untuk mencari stem (kata dasar) dari kata hasil filtering dengan cara menghilangkan imbuhan seperti berupa awalan dan akhiran. Salah satu library yang bisa digunakan dalam melakukan proses stemming bahasa indonesia adalah dengan menggunakan Library Python Sastrawi. Proses Stemming disajikan pada Tabel 5.

Tabel 5. Proses stemming

\begin{tabular}{ll}
\hline Sebelum & Sesudah \\
\hline $\begin{array}{l}\text { menyesal menjual tanah warisan ibunya anak } \\
\text { durhaka }\end{array}$ & sesal jual tanah waris ibu anak durhaka \\
\hline
\end{tabular}

\subsection{Klasifikasi Tweet}

Klasifikasi tweet dilakukan dengan menggunakan algoritma SentiStrength berbasis leksikon. SentiStrength memanfaatkan leksikal dengan sistem dual scale (positif-negatif), SentiStrength akan menghasilkan nilai yang positif dan nilai yang negatif. Nilai terbesar dari masing-masing emosi akan dikeluarkan sebagai hasil akhir. Keputusan akhir untuk menentukan kelas polaritas dari teks tersebut dilihat dari kelas emosi yang memiliki nilai terbesar. Sentiment lexicon (kamus sentimen) diperlukan sebagai acauan

IJAIDM Vol. 3, No. 1, March 2020: $21-27$ 
dalam menentukan sentimen yang terkandung pada komentar tweet. Banyak kamus yang tersedia untuk menentukan bobot nilai suatu kata. Pada penelitian ini digunakan kamus yang disusun oleh Devid Haryalesmana Wahid dan Azhari SN[13]. Total tweet asli hasil pengumpulan data dari Twitter yang berjumlah 500 tweet, dalam pengujian ini digunakan 454 data tweet hasil pre-processing.

Pada tahapan klasifikasi, data hasil praproses pada tiap kata akan dicocokkan terhadap isi leksikon apakah isi teks ada yang sama opinion words di leksikon. Jika ada, akan ditampilkan bobot dari kata tersebut[14]. Nilai akhir pada sebuah kalimat ditentukan dari skor positif tertinggi dan skor negatif tertinggi dari kata-kata penyusunnya, nilai ini menjadi kunci penentu polaritas dari data tweet tersebut. Tweet yang memiliki jumlah skor positif lebih besar dari skor negatif maka digolongkan pada sentimen positif, begitu sebaliknya. Jika tweet tersebut memiliki skor positif dan negatif yang sama, maka digolongkan dalam sentimen netral.

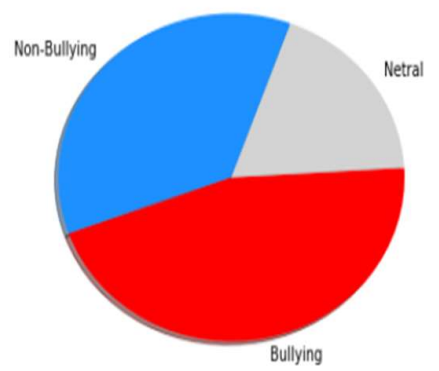

Gambar 2. Hasil Analisis Sentiment

Gambar 2 menunjukkan hasil analisis sentimen dari 454 tweet pengguna. Dengan persentase Bullying 45,3\%, Non-Bullying 36,2\% dan Netral 18,5\%. Diperoleh klasifikasi yang menunjukkan sentimen Bullying yang paling tinggi atau banyak. Meskipun, kata kunci scraping tweet yang digunakan di awalmenggunakan frasa dan kalimat yang mengandung unsur Bully, akan tetapi tidak menutup kemungkinan tidak diperolehnya tweet yang netral ataupun non-bullying di dalamnya.

Gambar 3 menunjukkan visualisasi dalam wordcloud yang menunjukkan kata-kata yang sering muncul dalam keseluruhan tweet. Dapat dilihat bahwa kata-kata bersifat negatif atau Bullying mendominasi di dalam visualisasi tersebut.

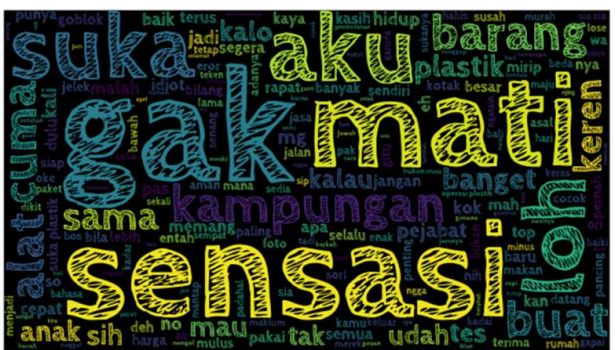

Gambar 3. Visualisasi WordCloud

\subsection{Pengujian Klasifikasi}

Hasil klasifikasi menggunakan SentiStrength menghasilkan kelas positive sentiment lebih banyak dari hasil pelabelan manual, jumlah kelas positive sentiment (Non-Bullying) dari klasifikasi SentiStrength berjumlah 161 sementara pelabelan manual menghasilkan klasifikasi 138 teks. Di kelas negative sentiment (Bullying), Sentistrength mengklasifikasikan 87 teks, dibandingkan pelabelan manual yang hanya mengklasifikasikan 65 teks sebagai negative sentiment. Berbeda dengan kelas netral, Sentistrength menghasilkan klasifikasi netral sebanyak 206, lebih sedikit 45 poin, dibandingkan pelabelan manual yang mengklasifikasikan 251 teks sebagai teks netral. Terdapat perbedaan antara sebuah algoritma dan manusia dalam menganalisis sentimen dari sebuah teks, hal ini dikarenakan manusia memiliki rasa dan emosi yang berbeda dalam memberi ukuran sentimen dari suatu teks. 
Tabel 6. Tabel Confusion Matrix

\begin{tabular}{llccc}
\hline & & \multicolumn{3}{c}{ Data Prediksi } \\
\cline { 3 - 5 } & & Non-Bullying & Netral & Bullying \\
\hline \multirow{3}{*}{ Data Aktual } & Non-Bullying & 85 & 13 & 40 \\
& Netral & 9 & 40 & 16 \\
& Bullying & 67 & 34 & 150 \\
\hline
\end{tabular}

$$
\text { Akurasi }=\frac{85+40+150}{454}=\frac{275}{454}=0.605=60.5 \%
$$

Berdasarkan perhitungan di atas diketahui bahwa hasil klasifikasi sentimen menggunakan SentiStrength memberikan akurasi secara keseluruhan sebesar 60,5\%, Akurasi menunjukkan seberapa akurat sistem dapat mengklasifikasikan data secara benar. Akurasi hasil penelitian ini sedikit lebih tinggi dibandingkan dengan penelitian yang telah dilakukan sebelumnya dengan akurasi sebesar 57.3\% [14]. Kamus leksikon SentiStrength dapat dimodifikasi untuk bahasa selain Inggris dengan menerjemahkan isi leksikon default-nya disesuaikan dengan aturan bahasa yang diinginkan. Pada penelitian tersebut menggunakan kamus default leksikon SentiStrength yang diterjemahkan dan disesuaikan dengan aturan bahasa Indonesia, akan tetapi terms di kamus default belum sepenuhnya sesuai dengan kebutuhan kosakata bahasa Indonesia. Sehingga nilai akurasi cenderung rendah.

Pada penelitian ini menggunakan kamus yang dikembangkan oleh Devid Haryalesmana Wahid dan Azhari SN[13], dimana Kamus sentimen didapatkan dari hasil translasi kamus sentimen berbahasa Inggris dan dilakukan pembobotan kekuatan sentimen oleh 3 orang ahli linguistik dari Universitas Gadjah Mada. Kamus sentimen ini juga terdapat data emosikon yaitu simbol-simbol yang biasanya digunakan untuk menggambarkan ekspresi wajah manusia, emosikon mempunyai bobot yang akan menentukan perubahan bobot sentimen pada sebuah kalimat. Selain itu juga terdapat data kamus idioms dan kata-kata tidak baku.

\section{KESIMPULAN}

Berdasarkan penelitian yang telah dilakukan, maka dapat disimpulkan:

1. Algoritma SentiStrength dapat digunakan dalam melakukan analisis sentimen di Twitter.

2. Dari 454 data tweet yang dianalisis diperoleh hasil sebanyak 161 tweet non-bullying (35.4\%), 87 tweet netral (19.1\%), dan 206 tweet bullying (45.4\%).

3. Berdasarkan hasil pengujian yang dilakukan didapatkan tingkat akurasi $60.5 \%$, karena terdapat perbedaan antara sebuah algoritma dan manusia dalam menganalisis sentimen dari sebuah teks, hal ini disebabkan manusia memiliki rasa dan emosi yang berbeda dalam memberi ukuran sentimen dari suatu teks.

\section{REFERENSI}

[1] C. D. Manning, P. Raghavan, and H. Schutze, Introduction to Information Retrieval. Cambridge: Cambridge University Press, 2008.

[2] D. H. Wahid and A. SN, "Peringkasan Sentimen Esktraktif di Twitter Menggunakan Hybrid TF-IDF dan Cosine Similarity,” IJCCS (Indonesian J. Comput. Cybern. Syst., vol. 10, no. 2, p. 207, Jul. 2016.

[3] F. Z. Tala, "A Study of Stemming Effects on Information Retrieval in Bahasa Indonesia," M.Sc. Thesis, Append. D, 2003.

[4] M. M. Pandie and I. T. J. Weismann, "Pengaruh Cyberbullying Di Media Sosial Terhadap Perilaku Reaktif Sebagai Pelaku Maupun Sebagai Korban Cyberbullying Pada Siswa Kristen SMP Nasional Makassar," J. Jaffray, 2016.

[5] M. Rashmi, "Introduction to Information Retrieval Systems," Int. J. Recent Innov. Trends Comput. Commun., vol. 3, no. 4, pp. 2051-2054, 2015.

[6] M. S. Mubarok, Adiwijaya, and M. D. Aldhi, "Aspect-based sentiment analysis to review products using Naïve Bayes,” in AIP Conference Proceedings, 2017, p. 020060.

[7] M. S. Neethu and R. Rajasree, "Sentiment analysis in twitter using machine learning techniques," in 2013 Fourth International Conference on Computing, Communications and Networking Technologies (ICCCNT), 2013, pp. 1-5.

[8] M. Taboada, J. Brooke, M. Tofiloski, K. Voll, and M. Stede, "Lexicon-Based Methods for Sentiment Analysis," Comput. Linguist., vol. 37, no. 2, pp. 267-307, Jun. 2011.

[9] M. Thelwall, "The Heart and Soul of the Web? Sentiment Strength Detection in the Social Web with SentiStrength," 2017, pp. 119-134.

[10] M. Thelwall, K. Buckley, G. Paltoglou, D. Cai, and A. Kappas, "Sentiment strength detection in short informal text,” J. Am. Soc. Inf. Sci. Technol., vol. 61, no. 12, pp. 2544-2558, Dec. 2010.

IJAIDM Vol. 3, No. 1, March 2020: $21-27$ 
[11] M. Thelwall, K. Buckley, and G. Paltoglou, "Sentiment strength detection for the social web," J. Am. Soc. Inf. Sci. Technol., vol. 63, no. 1, pp. 163-173, Jan. 2012.

[12] R. Nasrullah, Media Sosial: Perspektif Komunikasi, Budaya, dan Sosioteknologi. 2015.

[13] R. Sianipar and E. B. Setiawan, "Pendeteksian Kekuatan Sentimen Pada Teks Tweet Berbahasa Indonesia Menggunakan Sentistrength," e-Proceeding Eng. Vol.2, No.3 Desember 2015, 2015.

[14] S. Ceri, A. Bozzon, M. Brambilla, E. Della Valle, P. Fraternali, and S. Quarteroni, "An Introduction to Information Retrieval," in Web Information Retrieval, Berlin, Heidelberg: Springer Berlin Heidelberg, 2013, pp. 3-11.

\section{BIBLIOGRAFI PENULIS}

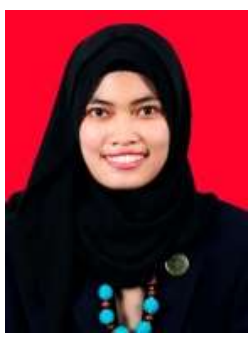

Ulfa Khaira, Dosen Program Studi Sistem Informasi Universitas Jambi. Memperoleh gelar sarjana dari Program S1 Ilmu Komputer Institut Pertanian Bogor tahun 2012. Kemudian melanjutkan studi pada kampus yang sama dan memperoleh gelar magister komputer pada tahun 2015. Tertarik pada penelitian bidang Geoinformatics dan Data Mining.

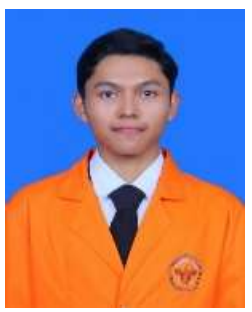

Ragil Johanda, Mahasiswa asal Jambi yang sedang menempuh studi S-1 Pada Program Studi Sistem Informasi Universitas Jambi.

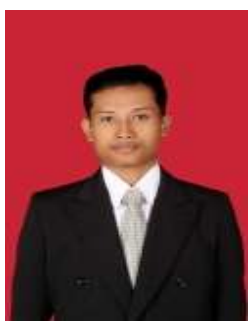

Pradita Eko Prasetyo Utomo, Dosen Program Studi Sistem Informasi Universitas Jambi. Memperoleh gelar S.Pd dari Universitas Jambi, dan gelar M.Cs dari Universitas Gadjah Mada. Minat Penelitian saat ini pada bidang data mining dan machine learning.

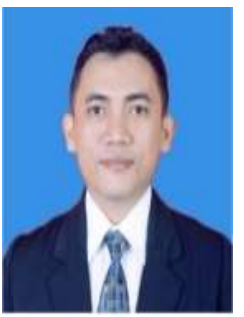

Tri Suratno, Dosen Program Studi Sistem Informasi Universitas Jambi. Menempuh pendidikan S1 di Institut Sains \& Teknologi AKPRIND Yogyakarta, S2 Magister Sistem Informasi di Universitas Diponegoro. Minat Penelitian saat ini pada bidang manajemen sistem informasi. 